\title{
One man's quest for the truth
}

\author{
The Cure for Everything! Untangling \\ the Twisted Messages About Health, \\ Fitness and Happiness \\ Timothy Caulfield \\ Viking Canada; 2012
}

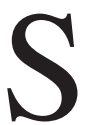

o what does a Canada Research Chair in Health Law and Policy do for kicks? If the research chair in question happens to be Timothy Caulfield, he treats himself like a human guinea pig in a quest to both improve health and to get a glimpse into the shady world of false promises that glitter like diamonds from the covers of glossy magazines.

While on summer holiday, Caulfield, a professor in the Faculty of Law at the University of Alberta, attended a talk on "detoxification" where he was told, "Ninety-five percent of all disease is caused by a build-up of acid in our bodies." And of course for just $\$ 40$ he was given the opportunity to buy his own cure for virtually everything. That led him to wonder: "Is there a cure for everything?" To find out, he explored the truths, benefits and science behind some of alternative health's most popular promises.

While, at least theoretically, as medical professionals, we may have it a tad easier than Caulfield, the average consumer certainly doesn't, and Caulfield, using himself as a sample size of one, goes on a year-long health walkabout in the land of outrageous claims. His methodology is easy to describe: seek out experts and use them, along with the medical literature, as evidence-based litmus tests for the claims we're all bombarded with. From consulting naturopaths and personal trainers, to seeking out skeptics and world class researchers, Caulfield paddles through the never ending mire of promised miracles. And while his bottom-line message might not be terribly surprising — "there are no magical cures or programs" - his smooth writing style, coupled with the

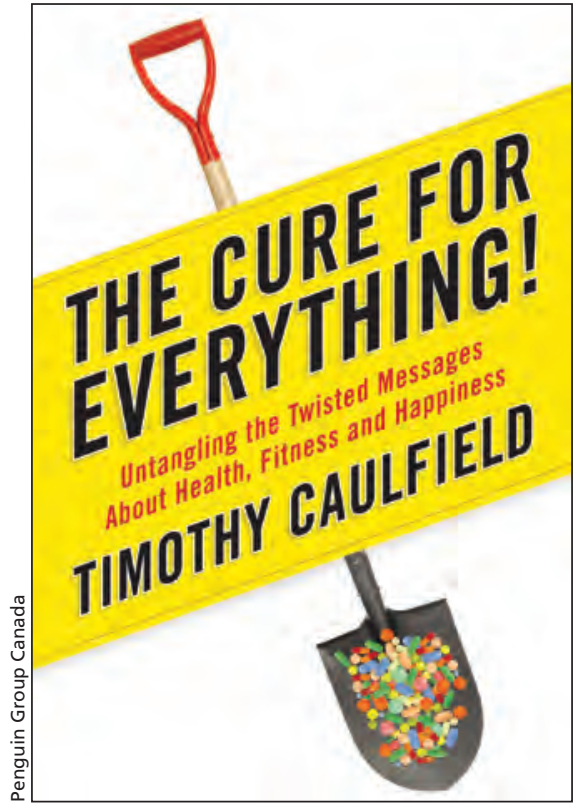

perfect blend of self-deprecating laughout-loud humour and honed by years of academia intelligence, make this a phenomenally entertaining read.

The one area where I think Caulfield falls somewhat short is with weight management and diet. Caulfield subscribes to what one might describe as the "die" with a " $t$ " version of diet in that he approaches weight loss, as do most modern day dieters, through suffering. He becomes the poster child of eat less, exercise more which while on paper is truthful, in practice is nonsustainable, which may well be one of the reasons why society struggles so hard in maintaining weight loss. This goal-oriented, suffer-till-you-get-there, then-quit approach is highlighted by Caulfield's last paragraph where he joyfully allowed himself many of the foods he'd been denying during his year-long experiment. As I regularly tell patients, "If you don't like the life you're living while you're losing, eventually you'll go back to the life (and the weight) you lived before you lost."

On his blog, Dr. Arya Sharma, scientific director of the Canadian Obesity Network, also takes issue with what he calls Caulfield's "disdain" for his body fat and wonders why a man whose body fat percentage at the experiment's outset is a normal $18 \%$, would want to try to reduce it. ${ }^{1}$ Sharma posits that Caulfield's equation of body-fat percentage with health is part and parcel of the very damning and non-evidence-based messages about diet and health that Caulfield himself set out to debunk, and really it's those sorts of messages that in turn have fueled what has become an enormous industry of self-help tomfoolery.

How is it that those messages Caulfield calls "twisted" even exist? For me, what Caulfield's experiences best highlight is the woeful job our government has done in preventing the health fraud that preys on society's vulnerability to false promises and overblown hope. How is it that anyone with a shingle or a website can make health-related promises? Shouldn't consumers be afforded more protection from practices that at best can be described as non-evidence-based?

On the one hand, it's an unforgivable shame that our regulatory agencies and governments have allowed our societies free rein in promoting modern Barnum and Bailey-style miracles. On the other hand, had they actually responsibly regulated health-related quackery out of existence, we'd have never had the pleasure of Caulfield's book.

\section{Yoni Freedhoff MD}

Assistant Professor of Family Medicine University of Ottawa

Ottawa, Ont.

Dr. Freedhoff is the medical director of the Bariatric Medical Institute and author of a forthcoming book from Simon and Schuster on the fallacies of modern day dieting.

\section{Reference}

1. Arya Sharma. The cure for everything, or not? [blog entry]. Edmonton (AB): Dr. Sharma's obesity notes; 2012. Available: www.drsharma.ca/the-cure-for -everything-or-not.html (accessed 2012 Apr. 15).

CMAJ 2013. DOI:10.1503/cmaj.120654 